\title{
Ecology and the aesthetics of imperfect balance
}

\author{
By Roderick Bamford
}

Roderick Bamford's practice traverses art, craft and design, with a specialization in ceramics. He works from a studio north of Sydney and lectures at the College of Fine Arts, University of NSW.

\begin{abstract}
Historically, craft values have provided a pivotal argument in the conflict between industrial and natural worldviews, concerning both the artefacts and social conditions of their creation. Today, the implications of carbon both as a fuel and a toxin demand a better understanding of the 'sign' values embedded in such dialogue, and inform responses to the dangers posed by dominant anthropocentric perspectives. Amidst the logic of a number of 'design for sustainability' arguments, craft emerges as an antidotal signifier to the combined impacts of hyper efficient production and rampant 'throw away' consumerism. Yet, in the carbon context, notions of benign impact and enduring value associated with craft can elicit contradictions. Drawing on literary arguments and examples in practice, this paper surveys relationships between craft and design as instruments of sustainability theory. Whilst recognizing the importance of qualitative factors in this context, and the increasing attention given to them in research, the critique emerges largely from a more established quantitative, or measured perspective. The relevance of this approach is attributed to the primacy of material outputs in both craft and design practice. In this context the writing aims to address a comparative gap in the discussion of practices in craft and design, and to contribute to a deeper understanding of their relationship. In seeking possibilities for craft within a discipline of sustainable culture, it explores a role for aesthetics in the context of what may be considered unnecessary artifacts.
\end{abstract}

\section{Paper}

Increasingly, the term 'sustainability' pervades our vocabulary, but is in danger of losing tangible value due to its application in multiple contexts and with various meanings. Amongst these, sustainability can be understood in terms of climate change, the practice of recycling, or the challenges of cultural or economic survival. In the broader ecological context, sustainability concerns a restoration of balance for species longevity, and for this to be realised on global and local levels, human decisions and actions need to benefit the interactive workings of natural, socio cultural, manufactured and economic systems. Such connections highlight the importance of time and scale in understanding relationships between sustainability and ecology. Macnaghten (2006) outlines differing but useful theoretical positions that inform this perspective. Firstly, there appears 
the anthropocentric idea that nature is global and original, from which human activity is intrinsically separate, a commonly held conservation view. Nature can also be considered as a chain of being to which everything belongs, including humanity. In a third instance, there is the idea that nature has always been shaped by socio-cultural forces. As these arguments all identify nature as a unit of analysis and politics, decisions regarding it will be measured on human terms, with the role of nature personified. However, within the anthropocentric hegemony, concepts of dominance and co-existence continue to collide. Nature as an autonomous entity is responsible for itself, yet it is lived within, tamed and exploited for our purposes. Until recently times it appeared stable and immune to human actions.

Consistent with the ecological concept of carrying capacity, ecological footprint calculators ${ }^{1}$ measure the amount of resources, expressed in either resource or geographic terms, needed to sustain a condition of living in perpetuity. These analytical tools help individuals and organisations analyse their impact on the environment in terms of consumption. The result of completing any one of the computations will most likely contend that, if you live in a 'developed' country, more resources are required than are globally available to support life as you have described it. With the confidence of a quarter millennium's industrial progress, refocusing human endeavours on technical innovations provides hope that new, low carbon energy solutions will prevail. Sequestering bad gas, cladding the world's desert with solar cells, encircling valleys with wind turbines or speckling the atmosphere with stratospheric wind kites (Griffith, 2010) offer the energetic prospect of supporting the globe's growing population to some degree. However, recent investigations of such a future scenario suggest limits in the capacity of clean energy production technologies to stabilize global climate (Hoffert, et al, 2002, p.981). The trajectory of climate change, even if all carbon dioxide emissions were to cease immediately, is predicted to bring, along with rising sea levels, huge population displacement and arable land degradation, compounding the shift in long standing patterns of human subsistence.

The substantial improvements in human prosperity resulting from greater control and exploitation of natural resources, largely food, fibre, fuel, timber and water, have cost more extensive ecosystem damage in the past 50 years than at any time in our history (Read, et al, 2005). By implication, old industrial models of managing of the world's ecosystems appear to have failed, requiring renewed efforts to simultaneously mitigate the current causes whilst developing protective solutions for the future. Established conceptual solutions to the sustainability problem appear to make common sense-a combination of efficiency, restraint, and repair. Humans need to moderate consumptive practices to achieve an acceptable balance between the speed with which we transform environmental resources and the rate the biosphere can renew them, whilst meeting demands of an increasing population, many of whom need, and

1 For example, calculators available from the Environment Protection Authority Victoria, accessible from http:// www.epa.vic.gov.au/ecologicalfootprint/calculators/default.asp 
aspire to improved standards of living. This idea is the conceptual source of the most commonly accepted definition of sustainability, that proposed in the Bruntland Report (1987). However, its encapsulation within the framework of sustainable development raises questions of how this should be evaluated. Reflecting on the primacy of economic growth as a significant measure of social value, incongruity becomes evident when comparing economic and ecological forms of growth. When ecosystems evolve, they develop, growing only by an amount supported by environmental limits, belying the condition that economy is a subsystem of ecology (Daley,1993, Ch.14). If Daly's arguments are correct, even the limits to economic growth proposed by the Brundland Report surpass the fundamental carrying capacity of the earth's ecology.

Despite apparent conviction in this argument, the qualitative implications of sustainability are far from clear. In assuming the necessity of some type of social conformity to enforce and manage the requirements of sustainable systems, our limited understanding of the complexity involved suggests that an ongoing critical exchange of values and relationships of power is necessary to avoid injustice. This is important in both moral and practical terms. Within the human sphere, the inseparable nature of social and economic development from sustainable development requires that their treatment cannot be effectively analysed separately, a factor apparent in recent debates surrounding the implementation of a carbon reduction schemes in Australia. Barbier (1987) reminds us that in rapidly developing world economies such as India, attempts to reduce environmental degradation are likely to fail unless the needs and participation of those most affected by the changes imposed are adequately addressed, and that both alleviating absolute poverty and providing secure livelihoods are necessary to minimize resource depletion, environmental degradation, cultural disruption, and social instability. Consequently a perspective can be reached for the simultaneous dematerialization of developed economies in order to mitigate the effects of consumption and environmental damage and accelerating development of marginalised communities most affected by such actions, whilst supporting important social and cultural dimensions in both. What could this mean for craft and design in developed economies?

Scerri \& James (2010) suggest that due to the increasing availability of quantitative indicators, a balance of qualitative indicators is urgently required to highlight the negotiated condition of social commitments. Nevertheless in their arguments for equivalence in identifying the values of both natural and social science viewpoints, the use of metrics is reinforced, highlighting the value of some form of accountability in the equation. The aesthetic perspective in craft and design may at first appear remote from such metrics, however in the materiality of these practices and their relationship to production and consumption, arguments emerge that instrumentally link craft and design to sustainability, in both environmental and cultural terms.

With the European Energy Commission estimating that over $80 \%$ of all productrelated environmental impacts are determined during the design phase (2009), design's critical role is under scrutiny. The primacy of physiological and 
material measures of success in consumer economies has informed design for sustainability, or eco design responses, that are largely instruments for efficiency. Eco design is conceptually optimized in McDonough \& Braungart's waste $=$ food metaphor (2002, Ch.4), where nutrients are happily separated into re-circulating biological and technical streams. Indigestible, undesirable toxic hybrids must be eliminated from the system to facilitate up-cycling, the ideal retransformation of technical matter. This beautiful paradigm resonates with human desire to reconnect with the nature it has lost through old industrialization and provides us with an equilibrium of materialism that has been a valuable recent model for design. Despite the success of Cradle to Cradle as a model for clean, carbon neutral production, it presents a streamlined account of interaction between material flows and organisms. The Cradle to Cradle solution accounts little for the differences in metabolic rates characteristic of biological and technical cycles. Biodegradable textiles that feed the forest to renew plant fibre stocks do so at slower rates than they can be extracted or up- cycled. This differential in the speed of transformation may moderate the ecological imbalance through a waste $=$ food metabolism, but the hunger of its high performance technical metabolism remains a threat to the biological one. Reflected in ecological terms, the dominant efficiency of one organism is altering the carrying capacity of the system.

The impact of decisions are highly leveraged in mass production systems, where small changes to the manufacture and distribution of everyday products have more far reaching environmental impacts than those associated with making of an iconic design or collectable work of art or craft. For this reason, analytical methods such as Life Cycle Analysis (LCA) and Materials Input Per Unit of Service (MIPS) are applied to manufacturing scenarios to reveal the cumulative environmental impact of manufactured products. Typically, they seek to attribute and quantify a range of pollution and resource impacts across the life of a product, from the point of extracting raw materials through to its manufacturing, use, and disposal. Through such studies we do not only learn about material efficiencies, but also their relationships to social practices. A recent study in the Netherlands (Ligthart and Ansems, 2007) compared the use of earthenware, porcelain, paper and polystyrene vessels as coffee drinking systems, concluding that ceramic cups are significantly more damaging to the environment. The surprising result appears to contradict convention that we should be designing and making things, which are beautiful, and long lasting, to extend their embedded natural capital. In the study, much of the impact was linked to the water, energy and chemicals used in washing the ceramic cup, which compounds the high-energy emission values of its manufacture. The report shows that even after 3000 uses the ceramic vessel has greater impact than the polystyrene or paper cups, and if one of the disposable cups were to be used twice, the discrepancies are more significant.

Such surprises are not confined to old technologies. Even high-tech manufacturing methods, such as solar panel production, can be far more 
inefficient than some traditional industrial processes such as injection moulding or metal casting, in some cases by three or six degrees of magnitude (Chandler, 2009).

A singular focus on carbon reduction largely addresses technical causes and the efficiency of mechanisms without adequately addressing their impact on human behaviour and consumption. In many products, the benefits gained from incrementally improved versions of products and services can lead to more frequent purchase upgrades or offsets, a factor that compounds with rising standards of living. For example, recent increases in average the size of Australian suburban houses have paralleled the introduction of energy efficiency rating schemes for homes and appliances, suggesting that energy savings are being negated by the need to heat and cool larger 'McMansion' spaces (Marten, 2009). Accelerated consumption associated with cycles of 'energy efficiency improvement' also appears to stimulate net increases in energy and resource use. These rebound effects create more demand for energy and 'pit conservation against environmental goals' (Saunders, 1992).

Design's widely documented industrial partnership has distanced craft from the modernist progress paradigm, but the implications for sustainability suggests a shift in relationships between design, material and time that demand social as much as technical innovation, including a significant shift in our relationship with material artefacts. It is here that the predisposition of craft comes into focus. In the philosophy or Bergson (1911), instinct is given greater importance than the mechanistic role of natural selection and fitness ascribed to Darwin's theory of evolution. Of the instinctive and vital capacities that characterize life, the capacity to organize, control, and manipulate matter is particularly human and separates us from nature. In placing intelligence within the faculty of artifice, Bergson (1911) realigned Homo Faber, a creator of tools, objects and machines, with the dignity of thinking in Homo Sapiens. Critically, he places creation as a life force, with intellect playing a fabricating role. This mode of being reflects an instinctive origin for both craft and design, and suggests that an attachment to transforming materiality is a both a signifier of humanity and a potential flaw contributing to un-sustainability.

There is a significant conceptual shift needed to design for sustainability. When creating satisfying solutions for our every need and desire, including those we don't yet crave, design provides conditions of comfort and convenience rather than need. Ezio Manzini (2005) describes this type of design, prevalent in the mass diffusion of consumer goods, as a largely a 'dis-enabling activity' that risks creating a population of 'incapables'. Dis-enabling is, in a sense, modernist functionality upturned. As more devices become surrogates for human activity, they reduce the need for us to exercise our faculties in the area of activity they replace, and create device dependence. The electronic calculator provides an extended capacity for us to undertake complex mathematics, yet over time, it numbs our capacity to undertake more simple arithmetic. Whilst we may be freed to concentrate more effectively on non-arithmetic activities, including other productive and enjoyable ones, our functionality is limited in the process. 
Consequently, it appears that as human activities become more specialised, we jettison versatility to our multifunctional devices. Certainly there is a legitimate use of technology to relieve monotonous pursuits and physical difficulties in life, but the value of its universal extension to all activities is questionable.

In the contradictory nature of humans, we may be inclined to lethargy as much as energetic motivation. We may evaluate actions in respect of opportunities presented to us and find satisfaction in completing a task for its own sake as much as for financial reward. Or it may be, in deciding to do something yourself, that both measures are satisfied. Manzini (2005) argues that design can be equally successful in 'enabling' individuals and communities to create positive impacts on society and the natural world, by engaging and exploring social and cultural worldviews, narratives, myths and metaphors in a process of creativity and re-conceptualization. Whilst he does not talk in terms of natural beauty per se, and recognizes the role of technology in achieving these aims, parallels can be drawn between his views on regenerating a social, ethical and ecological life balance and those William Morris sought to achieve through the repatriation of handwork in industrial England, a life of beauty intimately associated with the social conditions of individuals, particularly those engaged in work. Morris believed emphatically that beauty lived through work should become an intimate part of the everyday life of individuals. The drudgery of machines should be reserved only for the most distasteful and onerous tasks. The limited use of efficient machines, he considered, would liberate workers and the environment, reflecting their harmony in expanded pleasurable work (Macdonald, 2009). For makers or purchasers of craft, this coalition has remained a powerful tenet for 'well-being'.

Few exceptions can be found in 20th century design practice offering a framework for sustainability. Buckminster Fuller and Victor Papanek both championed the role of design as a more socially responsible profession; however, their approaches to achieving it differ. Fuller's 1950s proposal for comprehensive designing anticipated the need for a systematic approach based on closed loop relationship between resources, environmental capacity and human need. A decade later he called for a thorough analysis of the world's natural resources so they could be used more efficiently, and conceived of 'an electronic display that would provide a continual update of resource availability and use on a global scale' (Margolin, 1998, p.84). Fuller's ideas appear more evolved in the recent Massive Change mission led by Bruce Mau to re-design the world. Here the agency of designer leaves its familiar place between the client and consumer to occupy a sphere that encompasses both.

Within the utopian goals of Massive Change lie some valuable social insights for design linked to advancing technology, but also contradictions arising from its limitless application. This is exemplified in the book's manifesto (Mau and Leonard, 2004) which commits to housing the entire population of the earth in a safe, healthy and ideal urbanism, bringing unlimited energy to the whole world and eliminating the need for raw material by perpetually cycling products and their constituent matter. The structured arrangement of aphoristic word 
bites and images inspire through graphic design, but are less convincing upon analysis, appearing to rely on the aesthetics of persuasion to communicate the idea of a globally important utilitarian design tenet. Uncertainty over whether the arguments presented in the book rest upon aesthetics or ethics is also reflected in suggestions by Levit and Levy (p.173) that the purpose of Massive Change suffers from a confusion between design 'organizing or selling' the world.

Written around the time of the first oil crisis in the early 1970s, alternate scalar perspectives of design's responsibility appear in the work of an economist and a designer. In Design for the Real World, Victor Papanek (1971) harshly criticized design as a damaging contributor to the environment and humanity. Schumacher's book Small is Beautiful (1973), essentially critiques the excess of western economies, outlining a vision for a smaller, decentralized, human scale approach to development. Schumacher's economies of scale and Papanek's design approach both reflect sensibilities that emerged with the studio craft movement around that time, although Papanek's contribution appears more widely acknowledged in design circles. He proposed a shift away from mass consumer desire towards identified, often community centred need, drawing upon values inherent in indigenous cultures, and adopting the appropriate use of (low) technology.

The division between fast and large, and small and slow development paradigms is also reflected in their aesthetic dimension. Qualities of precision, efficiency, convenience and 'customization for personal identity' are commonly associated with the branded technical artefacts of mass production. In contrast, Papanek (1995, p.236) shifts the focus towards an aesthetic in design emerging from concepts associated with real changes in society and culture- ' a new direction transcending fad, trend or fashionable styling'. Although we may doubt the capacity of design's proliferate aesthetics to undo problems of its own making, the success of aesthetics as a strategy for aligning personal identity with products and services also points to design's capacity to redirect consumption towards more 'sustainable' identities or reduce its excess. For example, developing an aesthetic identity for furniture that attractively links the notion of repair or component upgrading with visual, material and ergonomic factors, could evoke in consumers an attitude towards servicing a sofa rather than discarding it, reversing the notion of designing for obsolescence. During the 1990's Droog designers explored how to influence the way designed objects are perceived over time. Marcel Wanders proposed the use of 'age metaphors' in furniture to build respect for the way objects wear, whilst the furniture assemblies of Tejo Remy reuse recycled furniture components (Ramakers \& Bakker, 1998, pp. 54-59). 


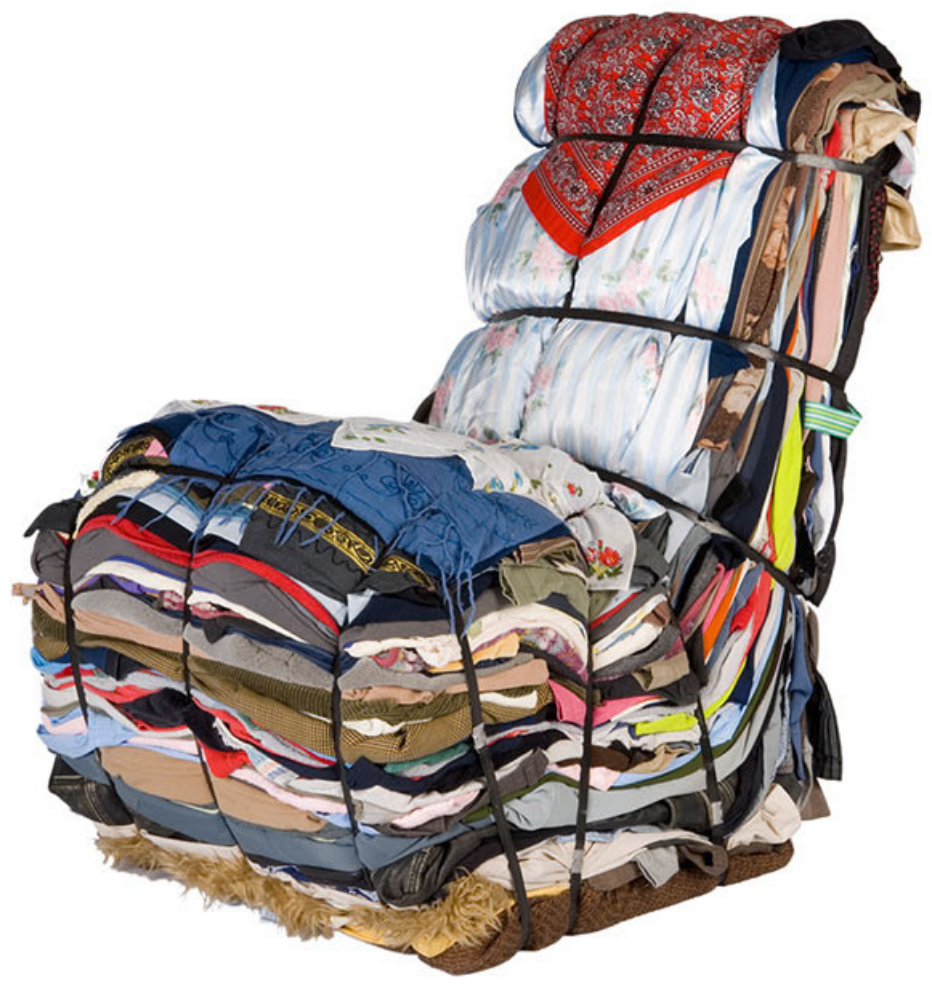

Plate 1: Tejo Remy, Rag chair for Droog, 1991.

Photo: Gerard van Hees.

The idea that aesthetics may not only emerge from but become active in sociocultural change is also a concern of Ezio Manzini, particularly in the relationship between aesthetics and technology in the design of products and services to enhance participation and social quality, and in the care of things. Importantly though, we need to understand that technology's apparatus has 'already transformed us, and has transformed what we think of as our environment' (Manzini, 1994, p.43).

Negotiating subjectivity through aesthetics is a hallmark of creative occupations; and there appears good reason to believe that this influential capacity can be applied to more complex scenarios and activate the notion of sustainable wellbeing. As an agent for responsible, participatory action in the transition towards this state, aesthetics can be directed towards the social and moral aims afforded by the visual, material and interactive qualities of artefacts. Aesthetics 
can also become 'a social attractor,' in the sense that it orients the choices of a multiplicity of individuals. It becomes a way of expressing a synthetic and therefore intelligible form, the complexity of a proposal (Manzini, 1994, p.43).

Patterns of consumption based satisfaction perpetuated by the rapid, serial turnover of individually owned products exacerbates the separation of responsibilities between supply and demand. Whilst the producer and their agents take care of the newborns, consumers and their agents dispose of the departed. To manage accelerating resource use and waste, tentative steps in systematic design have tried to address the socio-technical bifurcation of production and consumption. Product service system strategies seek to shift the emphasis from supplying a product to providing product service in terms of a lease, or deposit return system, thereby providing a mutual incentive for producer /consumer relationships or stewardship that shares responsibility for maximizing life cycle benefits. From shared ownership emerges the important idea of shared responsibility and the associated de-commissioning of 'single owner', 'single solution' attitudes to broader ecological problems. These have been shown, in some instances, to increase component recycling and reduce obsolescence (Kerr \& Ryan, 2001), offering a rehabilitative agency connecting the spaces between the disposing and making of things. Such 'stewardship" for things reflects a notion of care familiar to craft practice in the way it nurtures spirit and value in material through the human senses, and offers an opportunity for craft to fulfil those concerns in a cradle to cradle context, particularly at local or regional level. This would however require an expansion of craft's existing horizons regarding both the character and scale of occupation, in some ways similar to that which has occurred in design.

Csikszentmihalyi reminds us that in the construction of our identity from the artefacts we choose to surround us, aesthetics reflect the values exchanged, and that 'by actively appreciating the object, the owner joins in the act of creation, and it is this participation, rather than the artist's creative effort, that makes the artefact important in his or her life' (Csikszentmihalyi, 1991, p.26). This perspective supports an interactive social role for aesthetics as a factor contributing to the idea that artefacts prescribe social relations (Latour, 1992). In a semiotic study of everyday technical artefacts, Latour outlines how we have delegated competences to thousands of technological 'lieutenants', such as seat belts, door closers and hinges, so that our social relations are largely, but silently, prescribed by these non-humans. He concludes that 'knowledge, morality, craft, force, sociability, is not a property of humans but of humansaccompanied by their retinue of delegated characters. Since each of those delegates ties together part of our social world, it means that studying social relations without the non- humans is impossible' (Latour, 1992, p.169).

One visible gesture in recent sustainable design and craft approaches concerns the procedural aesthetics of materials. In both the empathetic expressions 
of original, natural materials and 'debrouillard'2 traditions that recycle postindustrial or post-consumer waste; craft conveys a sense of necessity and an empathetic, adaptive expression. Marlin Lundmark's teacup lamp (part of the 'Object Factory' exhibition at the NY Museum of Arts \& Design) (Lundmark, 2003) is an eloquent example of the three R's of rematerialized sustainability reduce waste, reuse finite resources, and recycle. In this work, the displacement of an industrial object's form with a new craft narrative of use ushers a second life, creates new meaning and appears to invoke associative empathy. Perhaps ironically, in an aesthetic deferment to the original object's memory of time and place, the work appears to incorporate a low efficiency incandescent bulb.

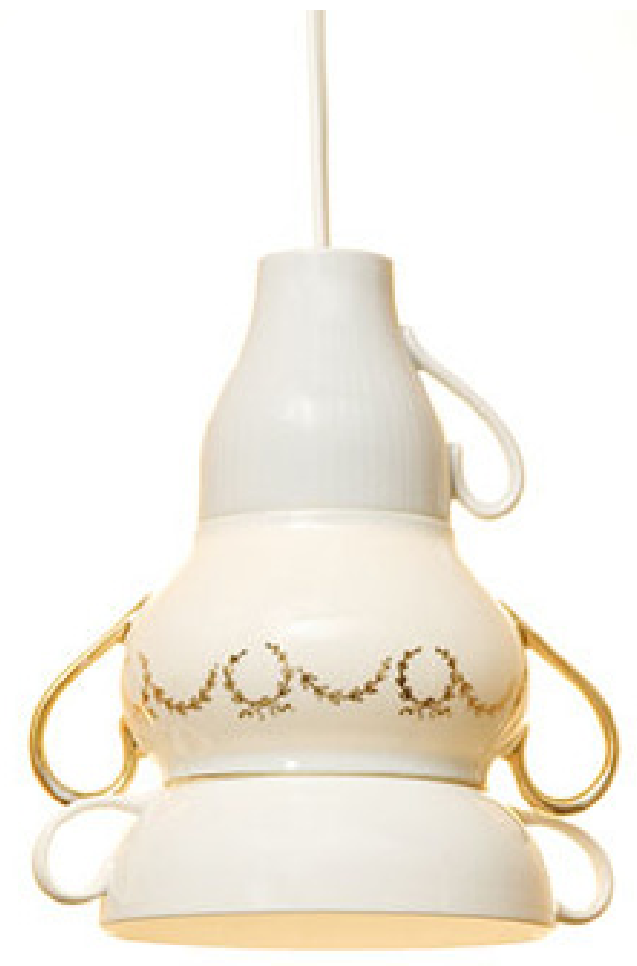

Plate 2: Malin Lundmark, Tea-cup-lamp, 2003, porcelain.

Photo: Stephan Lundberg, courtesy of Malin Lundmark.

Another prescriptive approach to sustainable social interaction with objects is to enrich the emotional attachment of an artefact, thereby extending the object's useful life, or at least delay its obsolescence. The interplay between human factors and functionality has received increasing attention since Dreyfuss (1955) introduced ergonomics to design. Norman (1998) revealed insights about the

2 A French term indicating someone who is skilled or resourceful at handling any difficulty. 
psychological relationship between humans and designed objects, and more recently Chapman (2005) has explored the role of emotion in the relationships that develop. In seeking to develop a commercially viable sustainable design approach that acknowledges the functional and physical transience of products, Stuart Walker re-constitutes discarded or unwanted products or things into a new, but ephemeral whole. Remarkably, in discussing the philosophy of this design, he draws on one of the tenets of craft practice for validation, stating that 'the artefact must illustrate the philosophy of sustainable design that I have been exploring. It must be achieved without mediation, drawings, or models, but rather through direct engagement' (Walker, 2003, p.191). Walker proposes a closer level of engagement in designing where ongoing, caring relationships are developed between people and the things they buy and use, replacing a more distant, objectified experience of product purchase. Walker ascribes to the essential characteristics of craft, not only a formative role in design, but iconic significance as a philosophy for sustainable practice. For those familiar with craft practice, the latter notion may also be intuited as nothing particularly new. Stuart Walker's earlier research (1994) also draws on aesthetics familiar to craft. By exploiting the visual and tactile complexity of natural surfaces, designers could furnish brand new productswith pre-worn surfaces to lessen the surprise that occurs, for example, when a shiny new kettle becomes tarnished. However in using 'wear patina' as an active bonding symbol between person and object, the design strategy could equally deny the transitional experience thatforms the bond. The implications arising from Walker's explorations are significant in that they not only legitimize craft practice within industrial design, but also offer an opportunity for craft to broaden its conceptual framework for practice.

Utility can contradict the value of emotional capital accrued in things. In use, an object may enhance personal attachment through sensorial familiarity and shared experience, whilst simultaneously increasing the potential for malfunction or breakage. For those objects in regular, everyday use, there is little categorical evidence that the crafted type outlive their industrially produced counterparts, emotionally or physically. The local bric-a-brac shop, the mantelpiece, and the museum reflect a re-use retail economy for artefacts, and, together with land fill sites, they acknowledge both their temporality and perpetuity. During the life of an artefact there are a range of exchanges between the creator and user that may be characterized as information, or a story. We are familiar with the range of strategies used to advertise brands, establish the credibility of what is for sale, or calibrate its use. In this exchange, the artefact's advertisement becomes a surrogate for the story of its creation, a qualification of its value and identity. However, following the initial purchase honeymoon, a satisfying ongoing relationship with the artefact may depend upon shared stories associated with its everyday engagement, as much as its designed or crafted providence. Although people develop emotional attachment with daily objects, there is no consistent pattern to its occurrence. For example, different age groups may favour objects differently, with older generations selecting artefacts for their memorial value and younger people attracted to the activity potential of objects (Csikszentmihalyi, 1991, p.27). Furthermore, the type of perennial attachment 
associated with a close emotional bond is linked to contextual experience, something that can only be vaguely proposed in the object's design. Examples include anheirloom that has been passed from one generation to another, or a chair that becomes special through being shared with the family. There is also the opportunity for people to contribute to the story of artefacts through their own personalization of them, such as the selection and arrangement of clothing, limited customization of products and accessories such as skins for mobile phones, or buying new homes. It also happens on a more crafted level, where people decorate backpacks, renovate the interior spaces of their homes or create gardens. A Delft University study of bicycle owners (Mugge, Schifferstein, and Schoormans, 2009) found a positive correlation between the level of energy individuals invested in personalizing a bicycle and their emotional attachment to it. They concluded that the corresponding self-expression had a positive impact on creating the emotional bond. In a sense, this self-expression builds a bond through narrative As Walter Benjamin observed,

\begin{abstract}
'the value of information does not survive the moment in which it was new. It lives only at that moment: it has to surrender to it completely and explain itself to it without losing any time. A story is different. It does not expend itself. It preserves and concentrates its strength and is capable of releasing it even after a long time.' (Benjamin, 1992, pp.89-90)
\end{abstract}

In this essay, Benjamin tells of an affinity between the pottery, weaving and storytelling, the oldest forms of craft. He casts the small, pre modern craft workshop as the home of storytelling, in which the travelling journeyman and resident master craftsman, also once a journeyman, work closely together. Here they combine 'the lore of faraway places, such as a much travelled man brings home, with the lore of the past, as it best reveals itself to natives of a place (Benjamin, 1992, p.85). Craft's long history of materializing relationships between humans, their place and time, connects us with the physical experience of environment, as opposed to an intellectual or virtual one. These stories offer a felt relationship, an experienced one, as opposed to many newer, designed relationships, often removed from tangible encounters with materiality or technology. For Benjamin, the storyteller is the artisanal form of communication, where 'traces of the storyteller cling to the story the way handprints of the potter cling to the clay vessel'(Benjamin, 1992, p.91).

In the rhythmic practice of crafts, listening is also enhanced, and as with reading an engrossing novel, the satisfaction of dwelling in the present involves an experience of time that integrates aspects of the past and the future within the scope of present thought. It is perhaps at this point of precarious balance in present time that an ecological aesthetic is best reflected. However, the aesthetic of balance, order, and harmony ascribed to nature is rarely static. It is a temporary equilibrium amidst the dynamic interaction of living species and nonliving forces that is constantly negotiated. Whilst our highly technical objects reflect aesthetics of comfort, uniformity and systematic control, they rarely reflect this aspect of the ecosystem supporting us. As we continue 'sustaining 
the unsustainable' (Fry, 2001, p.190), a point is reached where moderation and conservation are insufficient remedies, leading to the need for remediation and repair.

Tangible realizations of sustainability are likely to occur, uncomfortably, in the context of crisis. During the 1990s, a 'peak clay' condition in Japan threatened the social and cultural balance of a community that had grown dependent upon local material supplies. Faced with a shortage of quality local clay and exploration sites, the Historical Ceramics Centre of Gifu was faced with a problem of how to maintain the economy, industry and community wellbeing without becoming dependent upon imported raw materials. In 1997, the Green Life 21 (GL21) project responded (Watanabe, Kato, Hasegawa \& Hideki, 2000) by engaging local design and crafts, scientific research, government and businesses to collaboratively develop a network of shared solutions that stabilized and reinvigorated the community's deep cultural relationship with ceramics. The initial result included a system for recycling and re-manufacturing ceramic tableware, reduced carbon dioxide emissions, landfill, and extraction of some mineral resources associated with industrial activities. Against current global manufacturing trends, the deliberate introduction of craft strategies in the design, production and distribution of tableware appears to be a factor in the success of GL21. Minor visual and tactile imperfections in the finished

items arise from the variable qualities of post-consumer ceramic tableware collected from businesses such as hotels, and households. The characteristic variegation imparts a recognizable 'transitional' quality, yet the product is stronger and generates lower carbon dioxide emissions than comparable tableware made from imported materials. The meticulous attention to detail of 'Re-shokki' tableware, designed by Yoshikazu Hasegawa and Nobuo Sato, is directed towards improving product life, wash-ability and exchange serviceability. The 'One Dish Aid' range of confectionery containers, also made from recycled ceramic and designed by Hasegawa, is Japan's first product incorporating a deposit system for container reuse, replacing disposable plastic pudding containers. The 're-tableware' ceramics, including the Oliva dinnerware range designed by Prue Venables, became part of Japan's first 'resources circulation 'system, a collaboration of 32 local companies linked through an integrated recycling, manufacturing and service supply network. The recycled clay is also supplied to schools, universities and smaller ceramic studios (Hasegawa, 2009). 


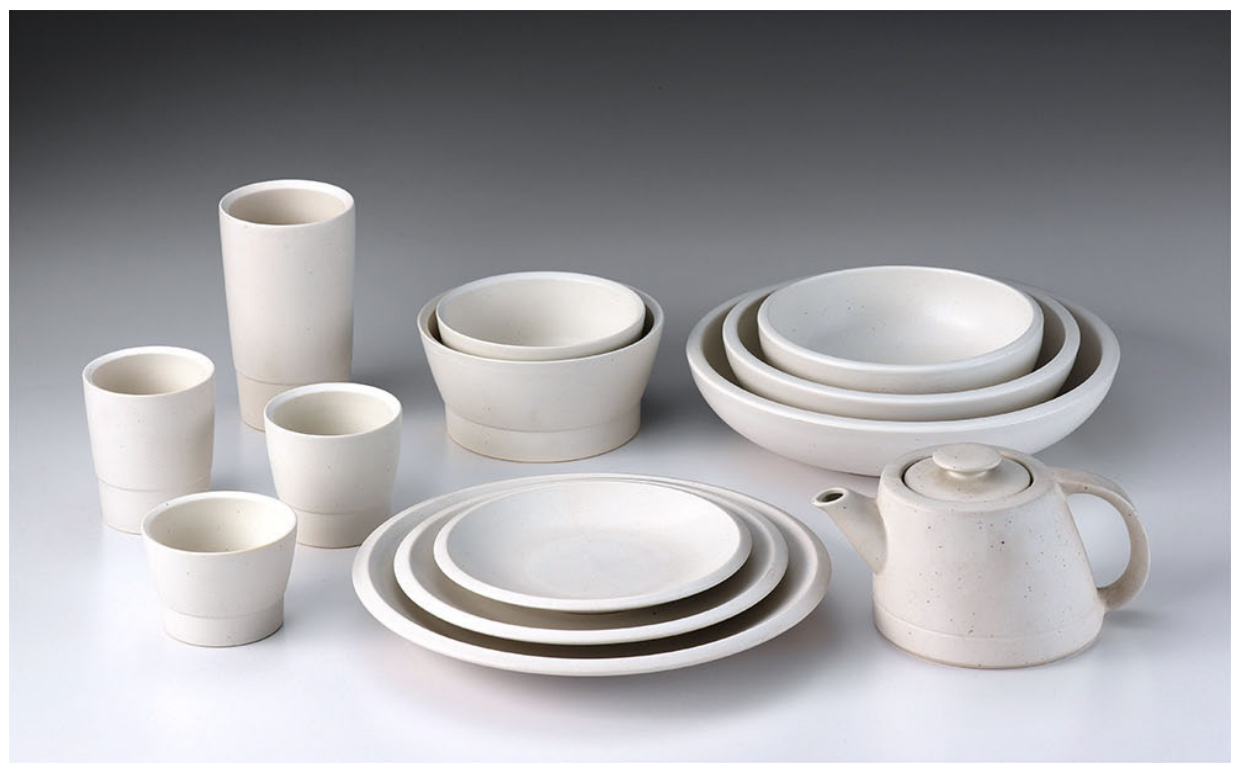

Plate 3: Recycled-Tableware "Re-Shokki-saisei-001", 2001, recycled porcelain. Designers: Nobuo Sato - Yoshikazu Hasegawa. Manufacturer: Green Life 21.

Photo: courtesy of Yoshikazu Hasegawa.

The mediation of environmental impact achieved through this industrial ecology is further transformed qualitatively in the integration of community practices that foster a local cultural ecology. GL21 deals with time in a new way that reflects and older parsimony, where repair and redirection are as important as seeking improved efficiency. At its centre are the rich traditions of Japanese craft that contribute in an iconic fashion to regional community benefits. The product is not exported, allowing the story of Re-shokki to circulate regionally, a living metaphor for the long-standing traditions of local Kintsugi that emerged from ancient frugal bowl stapling origins in China. Kintsugi celebrates the beauty of imperfection associated with the physical vulnerability of ceramics, the highly prized tea ceremony vessels visibly proclaiming the evidence of repair, powerful attractors that elicit devotion and care. Care, as a barometer of our morality, can be differentiated from fetishism. It includes not only our capacity to experience sensitivity, sympathy, and understanding of other people (or things), but extends to the responsibilities for our actions based upon them, and may involve a degree of constraint. 


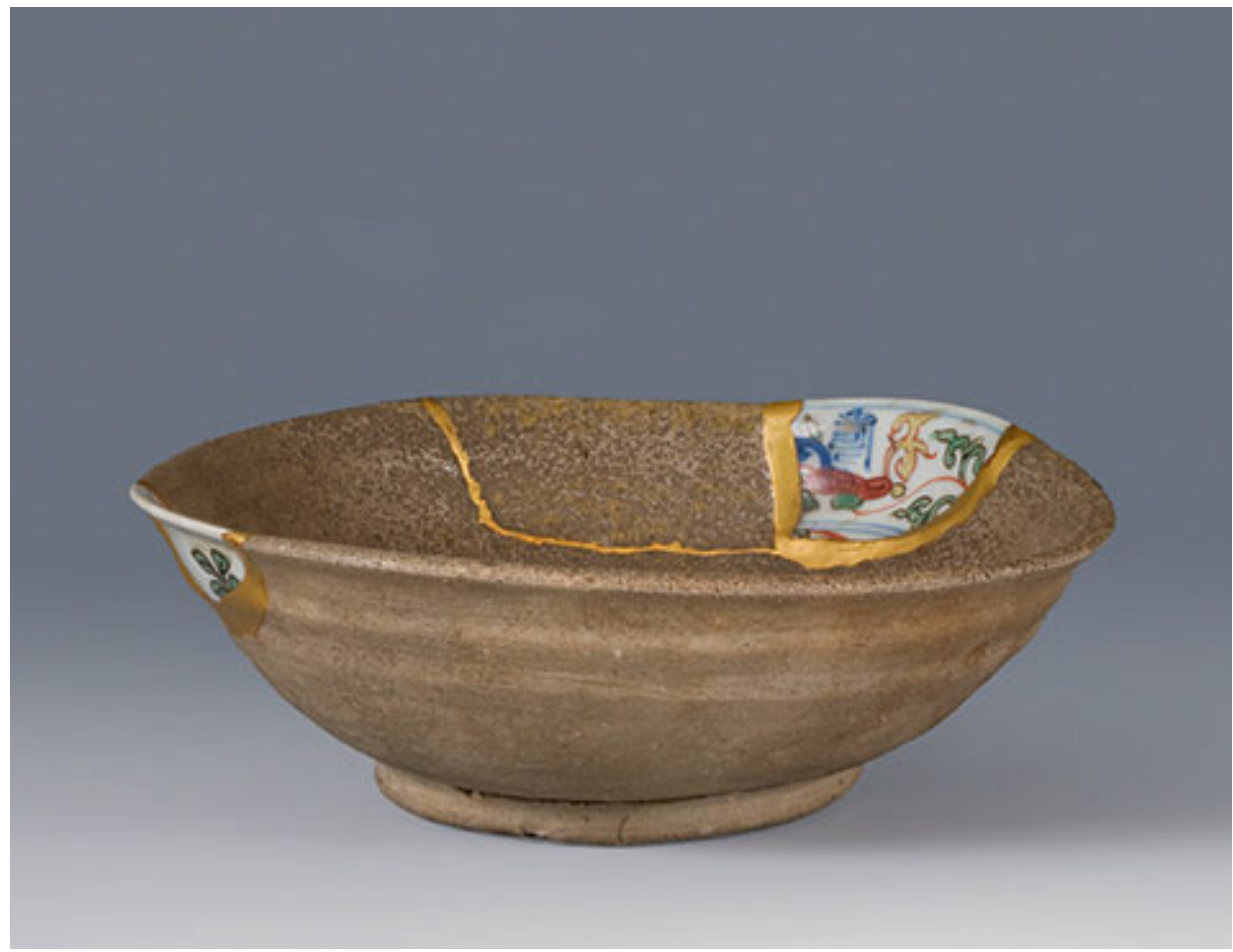

Plate 4: Teabowl (chawan), 15th century, Tokoname ware (yobitsugi-repairs with 18th century porcelain). Photo: Tomasz Samek, courtesy of Museum für Lackkunst, BASF Coatings $\mathrm{GmbH} \&$ Backmann/Eckenstein.

Although much responsibility rests with consumers, the emerging design approaches discussed in this paper highlight the important role creators can play in fostering care. It has also been argued that a number of these have their origins in craft, such as 'ecosocialist' thinking in the Arts and Crafts Movement (Macdonald, 2009). This suggests that craft practice has much to offer by clearly articulating its fundamental values.

The close socio-technical relationships historically reflected in craft practice could inform new, intimate understandings about our relationships with things outside of the singular object. There are opportunities for craft practice to more actively engage the social and technological particularities of the contemporary every day. In re-evaluating the epistemology of a sustainable self, craft could, for example, sensitise us to consumption by engaging in ways that activate, perhaps like the coalmine canary, the direction of our energies toward equilibrium in ecological exchange. In these interactions, directed by an ecological 'duty of care,' craft could produce 'change that, anthropocentrically, 'gives time' (Fry and Willis, 2004). Two apparent caring trajectories emerge from the possible future directions for craft. One, more watchful, responds adaptively and locally to the impacts of climate change, population pressures and resource limits. The other, at least in near future, is a more activated craft practice that 
builds transformative links with individuals and other professions to mitigate damaging ecological impacts, drawing on the role of the storyteller. In either case, extending our time will require, before making, more than contemplation. It will need systematic, interactive thinking, and acts of care inspired by ethical, ecological imagination.

\section{Bibliography}

Barbier, E., 1987, The Concept of Sustainable Economic Development. Environmental Conservation 14, pp. 101-110

Benjamin,W., 1992a, Illuminations. London: Fontana, pp. 89-90

Benjamin,W., 1992b, Illuminations. London: Fontana, p. 85

Benjamin,W., 1992c, Illuminations. London: Fontana, p. 91

Bergson, H., 1911, Creative Evolution. London: Macmillan, Ch. 3

Bruntland, G.(Chair), 1987, Report of the World Commission on Environment and Development: Our Common Future. [Online]. Available at: http://www. un-documents.net/wced-ocf.htm (Accessed 10 November 2009) Chandler, D., 2009, Manufacturing Inefficiency MIT TechTalk. Volume 53, Number 19, March 18, 2009. [Online]. Available at: http://web.mit.edu/newsoffice/ techtalk-back-2009.html (Accessed 7 April 2009)

Chapman, J., 2005, Emotionally Durable Design: Objects, Experiences and Empathy. London: Earthscan

Csikszentmihalyi, M., 1991a, Design and Order in Everyday Life. Design Issues (8)1, p. 26

Csikszentmihalyi, M., 1991b, Design and Order in Everyday Life. Design Issues (8) 1 , p. 27

Daly, H., 1993, Sustainable Growth: An Impossibility Theorem in Daly, H and Towsend, N., Valuing the Earth: economics, ecology. Cambridge: MIT Press, Ch 14, p. 268

Dreyfuss, H., 1955, Designing for People. USA: Simon \& Schuster. Viking, 1974

European Energy Commission. Eco-design of Energy-Using Products [Online] (updated 20 April 2010). Available at: http://ec.europa.eu/energy/efficiency/ ecodesign/eco_design_en.htm (Accessed 20 April 2009)

Fry,T. and Willis, A.M., 2004, Openings into the Ecology of Information Technology: Impacts of Information Technology Briefing Paper Part 1 [online] 
Available at: http://www.changedesign.org/Pathfinding/Archived/IIT/IITMain. htm (Accessed 8 July 2010) Fry,T., 2009a, Design Futuring: Sustainability, ethics and new practice. Oxford: Berg. p.120

Fry,T., 2009 b, Design Futuring: Sustainability, ethics and new practice. Oxford: Berg. p.190

Griffiths, S., 2006, Saul Griffith. Kites Tap Wind Energy: TED. [Online] Avaliable at: http://www.ted.com/talks/lang/eng saul_griffith_on_kites_as_the_future_ of_renewable_energy.html (Accessed 17 May 2010)

Hasegawa,Y., 2009, Personal correspondence and discussions (July 2009)

Hoffert, M. et al., Advanced Technology Paths to Global Climate Stability: Energy for a Greenhouse. Planet, Science, 1 November 2002, (298) 5595, pp. 981-987

Kerr, W. and Ryan, C., 2001, Eco-efficiency gains from remanufacturing. A case study of photocopier remanufacturing at Fuji Xerox Australia. Journal of Cleaner Production (9)1, pp.75-81

Latour, B.,1992, Where are the Missing Masses? The Sociology of a Few Mundane Artifacts, in Shaping Technology Building Society: Studies in Sociotechnical Change. USA: MIT Press, pp. 225-258

Levit, R. and Levy, E., Design Will Save the World! On Bruce Mau's Massive Change and the Mediatization of Culture. In: Saunders, W. ed., 2007. The New Architectural Pragmatism. Minesota: University of Minnesota Press. Ch 12, pp. 162-174

Ligthart,T. and Ansems, A., 2007, Single use or Reusable (coffee) Drinking Systems: An Environmental Comparison, TNO Built Environment and Geosciences Publications, NL, [Online](updated October 2007). Available at: http://tno.nl/downloads/2006-a-r0246e_b_summary.pdf (Accessed 20 June 2010)

Lundmark, M., 2003, Cup Lamp. [Online]. Available at: http://collections. madmuseum.org/code/emuseum.asp?emu_action=advsearch\&rawsearch =exhibitionid/,/is/,/47 2/,/true/,/false\&profile=exhibitions (accessed 15 July 2010)

Macdonald, B., 2009, William Morris and the Vision of Ecosocialism, In Contemporary Justice Review, (7)3, pp. 287- 304

McDonough, W. and Braungart, M., 2002, Cradle to Cradle: Remaking the way we make things. New York: North Point Press, pp. 92-117

McGinnis, M.V., ed., 1999, Bioregionalism. London: Routledge, p.2

Macnaghten,P., 2006, Nature. Theory, Culture \& Society, (23)347, pp. 2-3 
Manzini, E., 1994, Design, Environment and Social Quality: From "Existenzminimum" to "Quality Maximum". Design Issues, (10)1, pp. 37-43

Manzini, E., Enabling Solutions - Social innovation, creative communities and strategic design. Dis-Indaco,

Politecnico di Milano. [Online](updated 6 March 2005). Available at: http://www. dis.polimi.it/manzini- papers/05.03.06-Enabling-solutions.doc (Accessed 20 October 2009)

Margolin,V., 1998, Design for a Sustainable World. Design Issues, (14)2, pp. 84

Martens,P., 2009, Home truths: Australia trumps US when it comes to McMansions. Sydney Morning Herald, November 30, 2009 [Online] Available at: http://www.smh.com.au/national/home-truths-australia-trumps-uswhen-it-comes-to-mcmansions-20091129-jyva.html (Accessed 7 July 2010)

Mau, B. and Leonard, J., 2004, Massive Change. London: Phaidon

Mugge, R., Schifferstein, H. and Schoormans, J., 2004, Personalizing Product Appearance: The Effect on Product Attachment. Delft University of Technology. 2004 [Online]. Available at: http://static.studiolab.io.tudelft.nl/ gems/mugge/MuggeDE2004.pdf (Accessed 27 June 2009)

Norman, D.,1998, The Psychology of Everyday Things. New York: Basic Books

Papanek, V., 1971, Design for the Real World: Human Ecology and Social Change. New York: Pantheon Books Papanek, V., 1995, The Green Imperative: ecology and ethics in design and architecture. New York: Thames and Hudson. p. 236

Ramakers, R. and Bakker,G., 1998, Droog Design : Spirit of the Nineties. Rotterdam : 010 Publishers

Read, V., et al., 2005, Living Beyond Our Means : Natural Assets and Human Wellbeing. Millennium Ecosystem Assessment. Ecosystems and Human Well-being. (Online) Available at: http://www.millenniumassessment.org/en/ BoardStatement.aspx (Accessed 17 May 2010)

Saunders, H., 1992, The Khazzoom-Brookes Postulate and Neoclassical Growth. In Energy Journal, (13) 4, pp. 131- 148

Schumacher, E., 1973, Small is Beautiful: a Study of Economics as if People Mattered. London: Sphere Books, Ltd

Walker, S., 1995, The Environment, Product Aesthetics and Surface. In Design Issues, 11, 3, pp.15-27

Walker, S., 2003, Light Touch-The Design of Ephemeral Objects for Sustainability. In The Journal of Sustainable Product Design,3, p. 191 
Watanabe, T., Kato, K., Hasegawa, Y. and Hideki, I., 2000, Development of Recirculation System for Tableware,

Transactions of the Materials Research Society of Japan,2, pp. 661-663

Willis, A.M., 2000, Sight Unseen. Making and Unmaking Conference, University of Portsmouth, (updated 9 September 2000) [Online]. Available at: http:// www.teamdes.com.au/whatsold_main4.htm (Accessed 15 July 2010) 